\title{
Operating Frequency of Cobalt-Rich Crust Micro-terrain Detection in Simulative Deep-Sea Mining
}

\author{
Haiming Zhao, Yaqian Ji, and Qi Hao
}

\begin{abstract}
In the real-time micro-terrain detection of deep-sea cobalt-rich crust, the sonar detection performance is seriously influenced by the suspended sediments stirred up by the mining hob. To analyze the optimum detection frequency in deep-sea mining environment, a simulative system of deep-sea mining was built in laboratory. The acoustic attenuation in simulative deep-sea mining was calculated using the parameters measured in experiment, such as the temperature, salinity and concentration of suspended sediments. On this basis, the transmission loss and the volume reverberation were studied as a function of detection frequency and suspended sediment concentrations with a detection distance of two meters. Subsequently, the optimum detection frequency in severe reverberation environment was calculated with the help of active sonar equation. With the further consideration of vertical detection accuracy, the detection frequency in simulative deep-sea mining was finally determined. Results indicate that: 1) in simulative deep-sea mining, the suspended sediments induced acoustic attenuation and volume reverberation have a significant effect on detection frequency and cannot be ignored; the impact of suspended sediments on acoustic attenuation is much greater than volume reverberation; 2) both the transmission loss and the volume reverberation increase with increasing suspended sediment concentrations and detection frequency, and the detection frequency of the sonar detection system decreases with increasing particle concentrations; 3)the detection frequency in simulative deep-sea mining environment is confirmed to be $158 \mathrm{KHz}$ by taking acoustic attenuation, volume reverberation and vertical detection accuracy into account.
\end{abstract}

Index Terms - Simulative deep-sea mining, cobalt-rich crust, suspended sediments, acoustic attenuation, volume reverberation, detection frequency.

\section{INTRODUCTION}

Underwater acoustics detection is well-known as the most efficient and effective method at present for underwater target detection and location. The underwater sonar performance is seriously influenced by the marine environment factors such as suspended particles, internal wave, plankton, etc. In different environments, different factors pose the most significant hurdles to sonar propagation resulting in different challenges to a sonar system. The contribution of suspended sediments on sonar performance is

Manuscript received December 1, 2015; revised May 12, 2016. This work was supported in part by the National Natural Science Foundation of China (NO.51374245) and the Fundamental Research Funds for the Central Universities of Central South University (NO.2015zzts196).

Haiming Zhao is with State Key Laboratory of High Performance Complex Manufacturing, Central South University, Changsha 410083 China (e-mail: zhm0097@126.com).

Yaqian Ji and Qi Hao are with School of Mechanical and Electrical Engineering, Central South University, Changsha 410083 China (e-mail: saqlag_yaqian@sina.cn, qicai321@sina.com). derived from the severe acoustic attenuation and volume reverberation induced by suspended sediments. The real-time micro-terrain detection environments in deep-sea mining are characterized by short detection distance and high concentrations of suspended sediments stirred up by the mining hob. Hence, the effect of suspended sediments is significant to the sonar detection system design in this environment and needs to be taken into account to design an effective detection frequency.

Previously, many scholars have studied the effects of suspended sediments on sonar performance in coastal seawater. S. D. Richards [1]-[3] studied the effects of suspended sediments on sonar performance by analyzing the acoustic attenuation in shallow coastal waters and concluded that the suspended particulate matter had a significant effect on acoustic absorption and should be taken into account in sonar performance models. In 2005, PC Chu and M Cornelius [4] studied the effects of suspended sediment layer on the sonar imagery through volume scattering strength. In 2011, Colin W. Jemmott and William K. Stevens [5] studied the impact of reverberation on active sonar optimum frequency by means of analyzing the signal excess of a monostatic active sonar system in shallow water.

The above studies have been concentrated on minehunting sonar in shallow coastal waters characterized by long range (several hundred meters), moderate concentrations of order $0.1 \mathrm{~kg} / \mathrm{m}^{-3}$. While the applications of sonar in simulative deep-sea mining involve devices operating in the frequency range of $150-500 \mathrm{kHz}$ to realize the centimeter-level detection accuracy with the path lengths less than 2 meters [6], and the particle concentrations of order $10 \mathrm{~kg} / \mathrm{m}^{-3}$. In the collection of deep-sea cobalt-rich crusts, the deep-sea sediments may be stirred up by the mining hob and diffused into the detection zone, leading to severe acoustic attenuation and volume reverberation. Both of them may degrade the sonar detection performance and lead to the target echo undetected. Hence, in order to improve the sonar performance and the signal-to-reverberation ratio in simulative deep-sea mining, it is necessary to study the impact of suspended sediments on detection frequency and further determine an effectively detection frequency. To this end, a simulative system of deep-sea mining was built in laboratory in this paper. Subsequently, the detection frequency of sonar detection system in simulative deep-sea mining was determined by calculating the suspended sediments induced acoustic attenuation and volume reverberation.

\section{ACTIVE SONAR EQUATION}

The active sonar equation can be used to investigate the effect of suspended sediments on sonar performance such as 
the detection frequency. Though definitions of optimum frequency differ, it is generally the frequency which maximizes an optimality criterion such as maximum echo-to-noise ratio, maximum echo-to- reverberation ratio, and minimum propagation loss. The optimality criterion used in this paper is maximum probability of detection, which has a monotonic relationship with signal excess. Using signal excess as a proxy optimality criterion means that all terms in the sonar equation are used in determining the optimum frequency. The signal excess is calculated by the expression:

$$
S E=S L+T S-2 T L-R L-D T
$$

where $S E$ is the signal excess, $S L$ is the source level, $T S$ is the target strength, $T L$ is the transmission loss, $R L$ is the reverberation level, and $D T$ is the detection threshold. Each term has units of decibels. For a certain detection range, the optimum frequency of the sonar system can be obtained by maximizing the signal excess expressed by (1)

\section{A. Transmission Loss in Turbid Water}

Taking the geometric spreading losses into consideration, the transmission loss may be the sum of the geometric spreading and the volume attenuation, i.e.

$$
T L=20 \log (r)+\alpha r
$$

where $\alpha$ is the sound attenuation coefficient. The total attenuation coefficient in seawater containing suspended particles is considered as the sum of the attenuation due to clear water $\left(\alpha_{w}\right)$ and additional attenuation due to the sediment $\left(\alpha_{s}\right)$ [7], i.e.

$$
\alpha=\alpha_{w}+\alpha_{s}
$$

\section{1) Acoustic absorption in clear water}

Sound absorption in clear seawater may is the sum of absorption due to pure water, and that due to ionic relaxation processes involving boric acid and magnesium sulphate. One expression commonly employed for the seawater absorption is that due to Francois and Garrison [8], i.e.

$$
\alpha_{w}=10^{-3}\left[\frac{A_{1} P_{1} f_{1} f^{2}}{f_{1}^{2}+f^{2}}+\frac{A_{2} P_{2} f_{2} f^{2}}{f_{2}^{2}+f^{2}}+A_{3} P_{3} f^{2}\right] \mathrm{dB} / \mathrm{m}
$$

where, the three terms describe the contributions of boric acid, magnesium sulphate, and pure water respectively. And $f$ is frequency of the incident signal (in kilohertz), the $A_{i}(i=1,2,3)$ represent the temperature and salinity dependencies, $P_{\mathrm{i}}(i=1,2,3)$ are the pressure dependencies and $f_{i}(i=1,2)$ are the relaxation frequencies of boric acid and magnesium sulphate. These terms are given below.

$$
\begin{gathered}
A_{1}=\frac{8.86}{c} \times 10^{0.78 P H-S} \mathrm{dBkm}^{-1} \mathrm{KHz}^{-1}, \\
P_{1}=1, \\
f_{1}=2.8(\mathrm{~S} / 35)^{0.5} \times 10^{(4-1245 /(T+273))} \mathrm{KHz},
\end{gathered}
$$

$$
\begin{gathered}
A_{2}=21.44\left(\frac{S}{c}\right)(1+0.025 T) d B k^{-1} K^{-1} \\
\mathrm{P}_{2}=1-1.37 \times 10^{-4} \mathrm{z}+6.2 \times 10^{-9} \mathrm{z}^{2}, \\
f_{2}=\frac{8.17 \times 10^{(8-1990 /(T+273))}}{1+0.0018(S-35)} \mathrm{KHz} \\
\mathrm{A}_{3}=4.937 \times 10^{-4}-2.59 \times 10^{-5} T+9.11 \times 10^{-7} T^{2}-1.50 \times 10^{-8} T^{3}, \quad \mathrm{~T} \leq 20^{\circ} \mathrm{C} \\
\mathrm{A}_{3}=3.964 \times 10^{-4}-1.146 \times 10^{-5} T+1.45 \times 10^{-7} T^{2}-6.5 \times 10^{-10} T^{3}, \quad \mathrm{~T}>20^{\circ} \mathrm{C}, \\
\mathrm{P}_{3}=1-3.83 \times 10^{-5} z+4.9 \times 10^{-10} z^{2}
\end{gathered}
$$

where the $S, T$ are the salinity $(\mathrm{g} / \mathrm{kg})$ and temperature $\left({ }^{\circ} \mathrm{C}\right), c$ is the sound speed $(\mathrm{m} / \mathrm{s})$, and $z$ is the depth of the transducer (m)

\section{2) Additional attenuation by suspended particles}

The presence of suspended sediment leads to two additional attenuation mechanisms: viscous absorption and scattering. The viscous absorption arises from the phase lag between the sediment and the ambient fluid, due to the density of them being different. This leads to a velocity gradient in the boundary layer at the surface of the sediment which may make sound energy into frictional heat and hence acoustic absorption. The energy loss caused by the sound scattered out of the propagation direction is called scattering attention [1]. According to Richards [2], if the detection frequency is high and the particle radius is small, the attenuation due to scattering can be ignored due to its minor effect.

Urick [9] derived an expression for the viscous absorption attention coefficient based on principle of conservation of energy. The expression was used to the calculation of high frequency absorption by Wen [10], which can be written:

$$
\alpha_{s v}=\left(10 \log e^{2}\right)\left[\frac{\varepsilon k(\sigma-1)^{2}}{2} \frac{s}{s^{2}+(\sigma+\delta)^{2}}\right] \mathrm{dB} / \mathrm{m}
$$

where

$$
s=\frac{9}{4 \beta\left\langle a_{s}\right\rangle}\left[1+\frac{1}{\beta\left\langle a_{s}\right\rangle}\right], \delta=\frac{1}{2}\left[1+\frac{9}{2 \beta\left\langle a_{s}\right\rangle}\right]
$$

with $\varepsilon$ is the volume concentration of particles, $\mathrm{k}$ is the acoustic wavenumber, $\left\langle a_{s}\right\rangle$ is the mean particle radius, $\sigma=\rho_{s} / \rho_{o}$ and $\beta=\sqrt{\omega / 2 v}$, where $\rho_{s}$ and $\rho_{o}$ are the densities of the particles and ambient fluid respectively, and $\omega$ is the angular frequency of the incident pressure wave, and $v$ is the kinematic viscosity of the ambient fluid.

\section{B. Volume Reverberation Caused by Suspended Sediments}

In the process of deep-sea mining, there are bottom reverberation caused by bottom interface scattering and volume reverberation induced by suspended sediments. In deep-sea mining environment with high concentrated suspension of sediments, the volume reverberation dominates over bottom reverberation. The volume reverberation can be calculated by the following expression [11]: 


$$
R L=S L-40 \log (r)+S_{v}+10 \log (V)
$$

where

$$
V=0.5 c T \psi r^{2}
$$

is the volume of sediments which result in reverberation, and $T$ is the impulse width, and $\psi$ is the effective width in steradians of the two-way system beam illuminating the sediments; $S_{v}$ is the scattering strength. According to the volume reverberation theory, the scattering strength in turbid water is given by $\mathrm{Xu}[12]$ :

$$
S_{v}=10 \log \left(\frac{m_{s}}{\rho_{s} \frac{4}{3} \pi\left\langle a_{s}\right\rangle}\right)+10 \log \left(\frac{\left|f\left(k\left\langle a_{s}\right\rangle\right)\right|^{2} \cdot a^{2}}{4}\right)
$$

where $m_{s}$ is the mass concentration of the suspended sediments, and $\left|f\left(k\left\langle a_{s}\right\rangle\right)\right|$ is the magnitude of the form function and its simple semi-empirical expression is given by [13]:

$$
\begin{aligned}
\left|f\left(k\left\langle a_{s}\right\rangle\right)\right| \approx & \frac{\left(k\left\langle a_{s}\right\rangle\right)^{2}}{1+0.9\left(k\left\langle a_{s}\right\rangle\right)^{2}}\left\{1-0.35 \exp \left[-\left(\frac{k\left\langle a_{s}\right\rangle-1.5}{0.7}\right)^{2}\right]\right\} \\
& \cdot\left\{1+0.5 \exp \left[-\left(\frac{k\left\langle a_{s}\right\rangle-1.8}{2.2}\right)^{2}\right]\right\}
\end{aligned}
$$

\section{APPLICATION OF ACTIVE SONAR EQUATION IN SIMULATIVE DEEP-SEA MINING}

In the process of deep-sea mining, the deep-sea sediments stirred up by the mining hob are suspended in seawater and diffused into the acoustic detection zone. Energy attenuation of the incident and reflective sound wave may be caused by the suspended sediments. The severe energy attenuation of the incident sound wave may result in the target echo not be found in the received signal, as shown in Fig. 1 (a). It is the received signal in turbid water collected by the tiny-terrain acoustic detection system that is used for clear water [14]. Because of the acoustic attenuation and volume reverberation caused by the suspended sediments, though the acoustic system is well used for the tiny-terrain detection in clear water (as shown in Fig. 1 (b)), it may not be applied to turbid water with suspended sediments. Hence, in order to improve the tiny-terrain acoustic detection_system developed by our team, the optimum detection frequency in simulative deep-sea mining need to be studied with consideration of the suspended sediments on deep-sea mining_system.

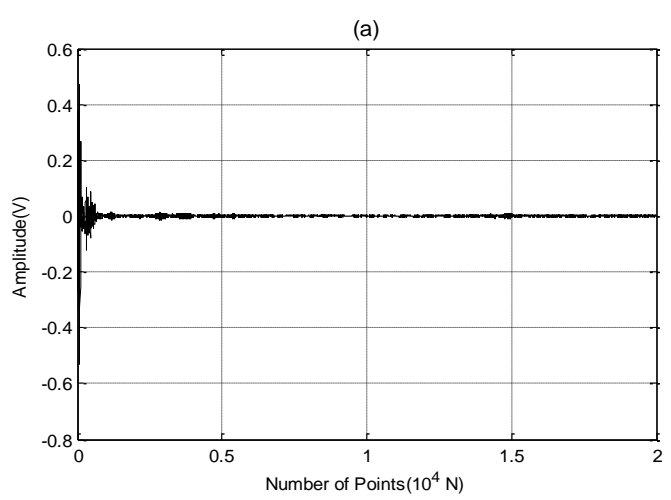

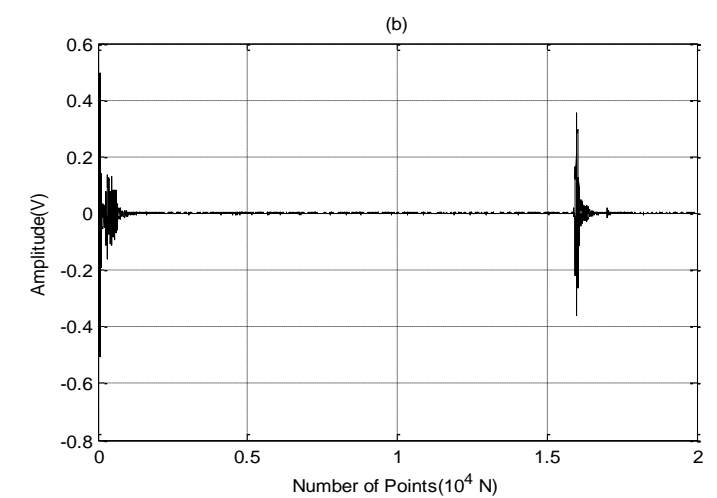

Fig. 1. Received signals collected by acoustic detection system used for clear water: (a) Received signal in turbid water; (b) Received signal in clear water.

\section{A. Concentration Measurement of Suspended Sediments in Simulative Deep-Sea Mining}

Considering a situation that the cobalt-rich crust is covered with deep-sea sediments, the quantity of the sediments stirred up by the mining hob would be the most. In this case, the suspended sediment concentration in detection zone would be largest. The suspended sediment concentration was measured assuming that the cobalt-rich crust is covered with deep-sea sediments.

The system studied in this paper is vehicle-mounted short distance ultrasonic detection system in deep-sea mining environment. Since the mining experiment is hardly to be done in deep sea because of a large size of mining device, an experimental apparatus of simulative deep-sea mining has been built in laboratory. The schematic of the simulative apparatus is shown in Fig. 2. The mining hob was simulated by helical blades and the transmit-receive transducer was mounted 1.5 meters in the front of the helical blade. The height of the transducer to the seabed was $1-1.5$ meters. The simulative seafloor sediments were cobalt crust fragments and miry sand on the bottom of the pool. The miry sand was distributed evenly on the cobalt crust fragments. The cobalt crust fragments were got by the spiral crusher developed our team and it was equal to boulderet in size ( $8-64$ in diameter) [15]. And the miry sand used in experiment was the mixture of loess and river sand at a ratio of 3:7. Since the marine geologic survey about multi-metal nodule shows that the average radius of deep-sea sediments is $0.85 \mu \mathrm{m}-2.23 \mu \mathrm{m}$ in the Pacific Ocean rich of cobalt crust [16], the river sand used in this paper was sieved by a standard test sieve of $0.063 \mathrm{~mm}$.

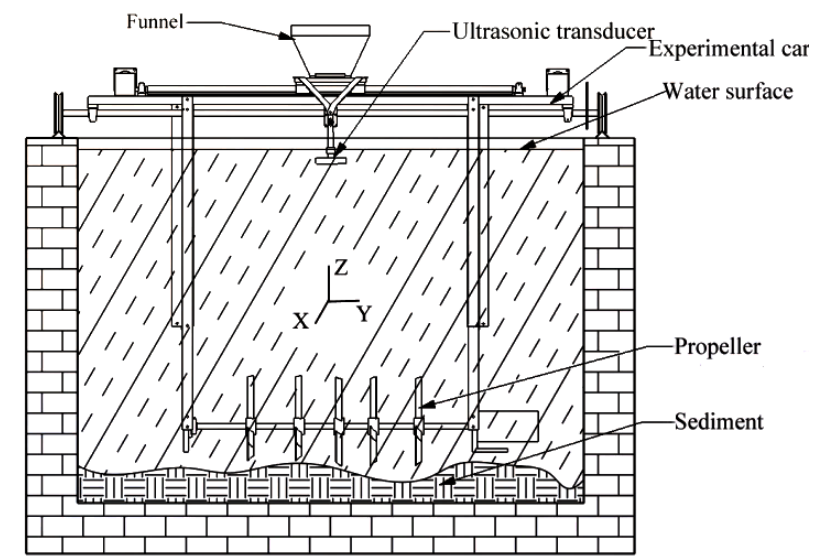

Fig. 2. Schematic of the experimental apparatus used to simulate deep-sea mining environment. 
Since the velocity of real mining process is low and the flow field around the transducer is less influenced by the mining hob, big cobalt crust fragments cannot diffuse into the detection zone. However, since the sediments are characteristic of small volume and light weight, they can be diffused into detection zone. To calculate the acoustic attenuation and volume reverberation in simulative deep-sea mining, concentrations of suspended particles along the central axis $(z)$ of ultrasonic transducer was measured by using of filtering and weighing method. To eliminate the man-made measuring errors, three samples were taken at the same point and the mean value of three concentrations was taken as the suspended sediments concentration at this point. Four points along each central axis which were $0.2 \mathrm{~m}, 0.4 \mathrm{~m}$, $0.6 \mathrm{~m}$ and $0.8 \mathrm{~m}$ away from the floor were measured as shown in Table I.

From the table, it can be seen that there is little difference between the four concentration values along central axis of the transducer. To be simplified, the concentrations of the four points are thought to be the same, and the mean values were used in the following calculation.

TABLE I: SuSPENDED SEDIMENTS CONCENTRATIONS AT DIFFERENT

\begin{tabular}{lllllc}
\multicolumn{5}{c}{ POINTS $\left(\mathrm{KG} / \mathrm{M}^{3}\right)$} \\
\hline Depth & $0.8 \mathrm{~m}$ & $0.6 \mathrm{~m}$ & $0.4 \mathrm{~m}$ & $0.2 \mathrm{~m}$ & Mean values \\
\hline $\mathrm{y}=0.8 \mathrm{~m}$ & 86.4 & 76.48 & 82.16 & 92.56 & 84.4 \\
$\mathrm{y}=0.4 \mathrm{~m}$ & 77.32 & 97.6 & 78.96 & 87.36 & 84.06 \\
$\mathrm{y}=0$ & 53.92 & 83.2 & 97.73 & 82.56 & 78.16 \\
$\mathrm{y}=-0.4 \mathrm{~m}$ & 38.8 & 58.88 & 61.28 & 92.8 & 62.94 \\
$\mathrm{y}=-0.8 \mathrm{~m}$ & 82.32 & 49.12 & 70 & 84.64 & 71.3 \\
\hline \hline
\end{tabular}

\section{B. Transmission Loss in Simulative Deep-Sea Mining}

Since the acoustic detection in this paper is characterized by short distance and high-frequency, it is think that the sound velocity, the salinity and the pressure are constant values in the detection process. The parameters measured in laboratory are salinity, temperature, pressure and density of the particles, and corresponding values are $S=35 \mathrm{~g} / \mathrm{kg}$, $T=16^{\circ} \mathrm{C}, P=1 \mathrm{~atm}$ and $\rho_{S}=1495 \mathrm{~kg} / \mathrm{m}^{3}$. The sound velocity calculated by the expression of [2] is $c=1510 \mathrm{~m} / \mathrm{s}$. On this basis, the attenuation coefficient was calculated with (3) as a function of detection frequency of interest and particle radius range of $0.1 \mu \mathrm{m} \sim 2.5 \mu \mathrm{m}$, as shown in Fig. 3 .

Fig. 3 clearly shows that 1) the acoustic attenuation coefficient increases with increasing detection frequency; 2) there is a significant effect of particle radius on the acoustic attenuation coefficient when the acoustic frequency above $100 \mathrm{KHz}$ and the acoustic attenuation coefficient reached to the maximum when particle radius is about $1.2 \mu \mathrm{m}$. Hence, the particle radius of $1.2 \mu \mathrm{m}$ is used in subsequent analysis in simulative deep-sea mining.

Fig. 4 shows the attenuation coefficient in simulative deep-sea mining as a function of acoustic frequency and particle concentration with the particle radius of $1.2 \mu \mathrm{m}$. It can be seen that the higher the frequency, the more significant of the influence of particle concentrations on attenuation coefficient. The peak in the small particle region (with radius of $1.2 \mu \mathrm{m}$ ) corresponds to the viscous absorption contribution. This is caused by the high particle concentrations in simulative deep-sea mining (as shown in Table I) and the small deep-sea sediments radius, leading to minor effect of scattering by suspended sediments.

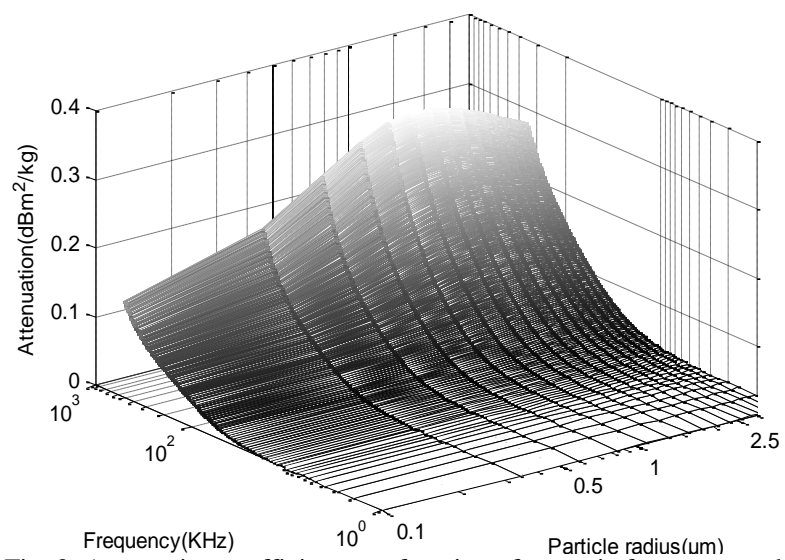

Fig. 3. Attenuation coefficient as a function of acoustic frequency and particle radius in simulative deep-sea mining.

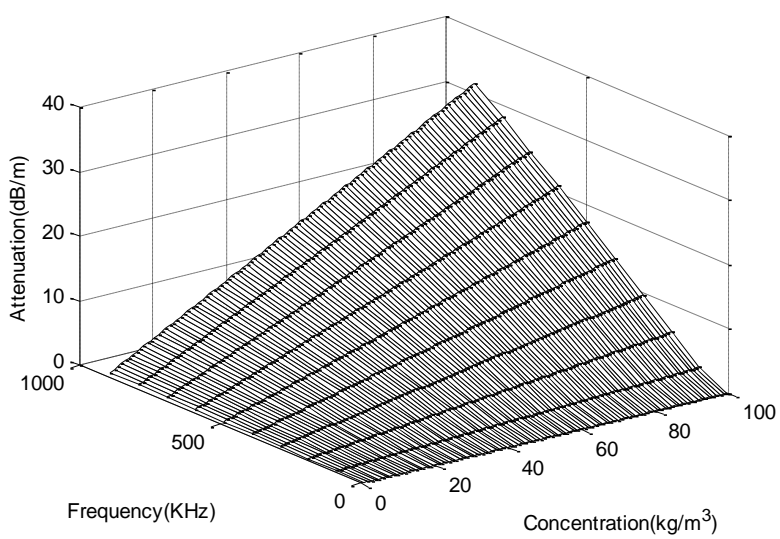

Fig. 4. Attenuation coefficient as a function of acoustic frequency and particle concentration in simulative deep-sea mining.

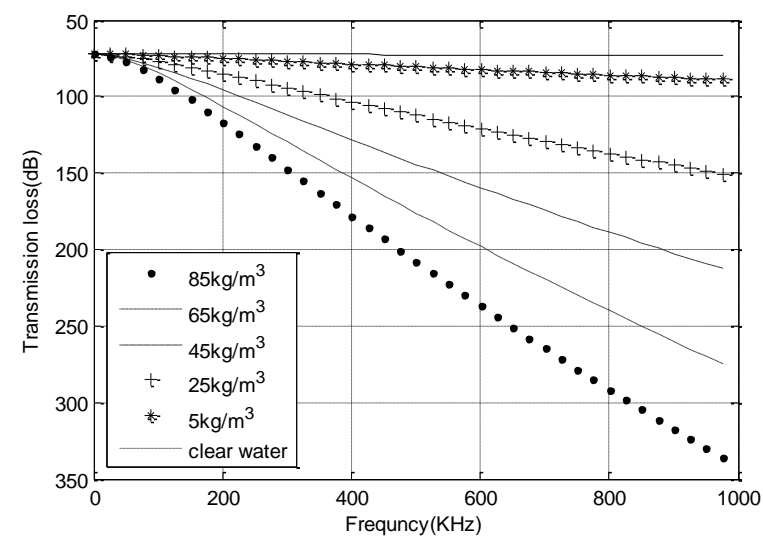

Fig. 5. Transmission loss (TL) as a function of frequency at suspended concentrations of $85 \mathrm{~kg} / \mathrm{m}^{3}, 65 \mathrm{~kg} / \mathrm{m}^{3}, 45 \mathrm{~kg} / \mathrm{m}^{3}, 25 \mathrm{~kg} / \mathrm{m}^{3}, 5 \mathrm{~kg} / \mathrm{m}^{3}$ and clear water.

Fig. 5 shows the transmission loss in simulative deep-sea mining as a function of frequency at suspended concentrations of $85 \mathrm{~kg} / \mathrm{m}^{3}, 65 \mathrm{~kg} / \mathrm{m}^{3}, 45 \mathrm{~kg} / \mathrm{m}^{3}, 25 \mathrm{~kg} / \mathrm{m}^{3}, 5$ $\mathrm{kg} / \mathrm{m}^{3}$, and clear water. The detection distance considered in this paper was 2 meters. Fig. 5 shows that the transmission loss at $85 \mathrm{~kg} / \mathrm{m}^{3}$ varies from $75 \mathrm{~dB}$ to $340 \mathrm{~dB}$. The suspended sediment concentrations have a significant effect on transmission loss. Hence, in the interested range of concentrations in simulative deep-sea mining, the transmission loss caused by suspended sediments need not be ignored in the design of an effective detection system. 


\section{Reverberation Level in Simulative Deep-Sea Mining}

The volume reverberation level considered in this paper was calculated by (6) at different suspended sediments concentrations as shown in Fig. 6. The volume reverberation level was calculated assuming that the source level was cavitation limited. It can be seen clearly that the volume reverberation level seriously depends on the detection frequency. In addition, the curves of volume reverberation level versus frequency at different concentrations are parallel to each other. And with frequency of $200 \mathrm{KHz}$, the volume reverberation level is $55 \mathrm{~dB}$ at a suspended sediments concentration of $85 \mathrm{~kg} / \mathrm{m}^{3}$, and the volume reverberation level at $5 \mathrm{~kg} / \mathrm{m}^{3}$ is $40 \mathrm{~dB}$. Clearly, different from the larger transmission loss caused by higher suspended sediments concentrations, the volume reverberation level has a small increase with increasing suspended sediments concentrations That is, the effect of suspended sediments on acoustic attention is more significant than volume reverberation.

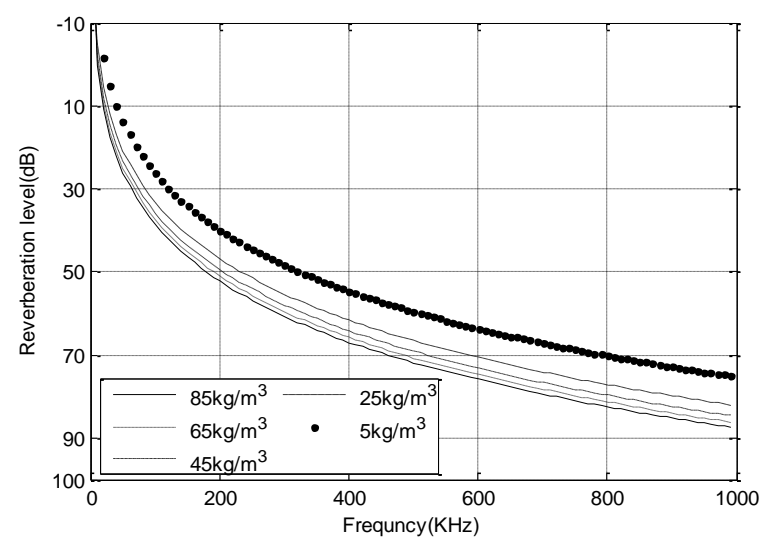

Fig. 6. Volume reverberation level (RL) due to volume scattering from suspended sediments. Volume reverberation level increases with both suspended concentrations and detection frequency.

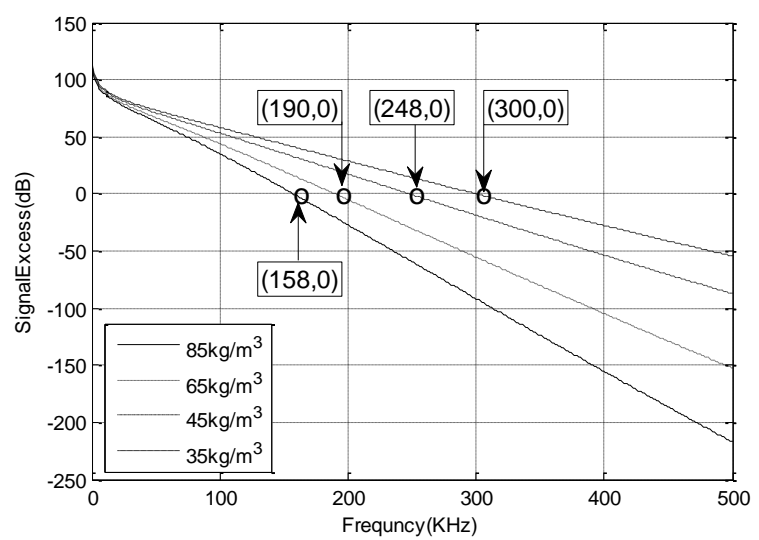

Fig. 7. Signal excess as a function of frequency at different particle concentrations.

\section{Detection Frequency in Simulative Deep-Sea Mining}

With the detection range of two meters in simulative deep-sea mining, the signal excess back to the transducer was calculated by (10). The signal excess as a function of frequency at different particle concentrations is shown in Fig. 7. As a contrast, the signal excess in clear water with no suspended sediments is shown in Fig. 8. The coordinate values of points on curves indicate the frequency at the signal excess of zero.

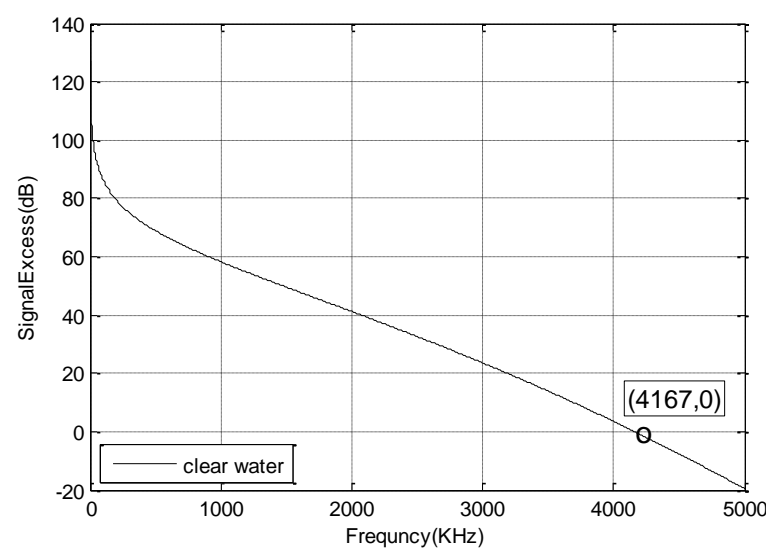

Fig. 8. Signal excess as a function of frequency in clear water.

According to underwater acoustics principle, the detection frequency that maximizes the signal excess is thought as the optimum frequency of the active sonar system. When signal excess is zero, it is the maximum frequency that the target echoes can be observed. It can be seen that the signal excess decrease rapidly with increasing frequency and suspended sediment concentrations. The maximum frequency decreases from $300 \mathrm{KHz}$ at a suspended sediment concentration of $35 \mathrm{~kg} / \mathrm{m}^{3}$ to $158 \mathrm{KHz}$ at $85 \mathrm{~kg} / \mathrm{m}^{3}$. While in water free of suspended sediments, the maximum frequency for the same sonar system may be up to $4167 \mathrm{KHz}$. In fact, the clear seawater environment with the detection ranges less than 2 meters is noise limited rather than reverberation limited. Besides, the acoustic attenuation in clear seawater is only the absorption of clear water which has a minor effect on sound transmission loss.

The vertical detection accuracy in simulative deep-sea mining need to be centimeter level, or the wavelength of the detection wave should be within $1 \mathrm{~cm}$. Hence, the minimum working frequency of sound waves is (the velocity of sound in the water is taken to be $c=1510 \mathrm{~m} / \mathrm{s}$ ):

$$
f_{\min }=\frac{c}{s}=\frac{1510}{1 \times 0.01}=151(\mathrm{KHz})
$$

The equation shows that in order to improve the detection accuracy, the detection frequency should be as high as possible. Hence, the detection frequency in simulative deep-sea mining is determined to be $158 \mathrm{KHz}$ in order to improve detection accuracy.

\section{EXPERIMENT AND RESULT}

To verify the detection frequency, the active sonar detection system was established. And with the simulative mining system built in laboratory, experiments were carried out with transducers at different frequencies. The propeller was driven by an adjustable-speed motor at a speed of $75 \mathrm{r} / \mathrm{min}$ to form the turbid water environment. At each detection point, the received signals were collected with the data acquisition card (PCI1714) and the suspended sediment concentration was measured with the filtering and weighing method. In the experiment, 10 points were measured at frequencies of $160 \mathrm{KHz}, 190 \mathrm{KHz}, 250 \mathrm{KHz}$, respectively. The suspended sediment concentration of each point and their detection performance are shown in Table II(a) and Table 
II(b). The symbol $\sqrt{ }$ indicates that the target echo is successfully observed in received signals; while $x$ indicates the target echo is not obtained in received signals.

TABLE II (A): EXPERIMENT RESULTS

\begin{tabular}{|c|c|c|c|c|c|}
\hline$\underbrace{\text { Concentration }}_{\text {Frequency }(\mathrm{KHz})}\left(\mathrm{kg} / \mathrm{m}^{3}\right)$ & 71.3 & 80.3 & 48.1 & 64 & 54.1 \\
\hline $160 \mathrm{KHz}$ & $\sqrt{ }$ & $x$ & $\sqrt{ }$ & $\sqrt{ }$ & $\sqrt{ }$ \\
\hline $190 \mathrm{KHz}$ & $\sqrt{ }$ & $x$ & $\sqrt{ }$ & $\sqrt{ }$ & $\sqrt{ }$ \\
\hline $250 \mathrm{KHz}$ & $x$ & $x$ & $x$ & $x$ & $x$ \\
\hline \multicolumn{6}{|c|}{ TABLE II (B): EXPERIMENT RESULTS } \\
\hline $\begin{array}{r}\text { Concentration } \\
\left(\mathrm{kg} / \mathrm{m}^{3}\right)\end{array}$ & 52.2 & 93 & 40.5 & 67.4 & 37.8 \\
\hline Frequency $(\mathrm{KHz})$ & & & & & \\
\hline $160 \mathrm{KHz}$ & $\sqrt{ }$ & $x$ & $\sqrt{ }$ & $\sqrt{ }$ & $\sqrt{ }$ \\
\hline $190 \mathrm{KHz}$ & $\sqrt{ }$ & $x$ & $\sqrt{ }$ & $x$ & $x$ \\
\hline $250 \mathrm{KHz}$ & $x$ & $x$ & $\sqrt{ }$ & $x$ & $x$ \\
\hline
\end{tabular}

It can be seen that the signal system with a frequency of $160 \mathrm{KHz}$ can effectively detected the target echoes with a probability of $88.9 \%$. The failure detection of the other 1 point with the suspended sediment concentration of $80.3 \mathrm{~kg} / \mathrm{m}^{3}$ is probably because of the large slope angle of the substrate.

\section{CONCLUSION}

In the real-time acoustic detection of cobalt-rich crust micro-terrain, server acoustic attenuation and volume reverberation may be induced by the suspended sediments stirred up by the mining hob. Based on the simulative mining system built in laboratory, the optimum frequency in simulative deep-sea mining are studied and conclusions can be summarized as follows.

1) In simulative deep-sea mining, the suspended sediments induced acoustic attenuation and volume reverberation have a significant effect on signal excess and hence on detection frequency.

2) Both the transmission loss and the volume reverberation increase with increasing suspended sediments concentrations and detection frequency, respectively. The suspended sediments induced acoustic attenuation is much greater than its volume reverberation.

3) With a detection range of 2 meters and a particle radius of $1.2 \mu \mathrm{m}$ in simulative deep-sea mining, the detection frequency is confirmed to be $158 \mathrm{KHz}$ with the overall consideration of the interested suspended sediments and the vertical detection accuracy. The results verified the frequency with a probability of $88.9 \%$.

\section{REFERENCES}

[1] S. D. Richards et al., "The effect of suspended particulate matter on sound attenuation in seawater," The J. of the Acoustical Society of America, vol. 100, no. 3, pp. 1447-50, 1996.

[2] N. R. Brown et al., "Measurement of viscous sound absorption at $50-150 \mathrm{kHz}$ in a model turbid environment," The Journal of the Acoustical Society of America, vol. 104, no. 4, pp. 2114-20, 1998.
[3] S. D. Richards et al., "The effect of suspeded particulate matter on the performance of high frequency sonars in turbid coastal waters," in Proc. Conf. on High Freq. Acou. in Shallon Water, 1997, pp. 443-450.

[4] P. C. Chu, M. Cornelius, and M. Wagstaff, "Effect of Suspended Sediment on Acoustic Detection Using Reverberation," Marine Technology Society Journal, vol. 39, no. 2, pp. 105-109, 2005.

[5] C. W. Jemmott and W. K. Stevens, "The impact of reverberation on active sonar optimum frequency," Proceedings of Meetings on Acoustics, vol. 12, no. 1, p. 3518, 2011.

[6] B. Yang, "Short-distance echo recogniton of cobalt-rich crusts in deepsea," Ph.D. dissertation, Dept. Mechanic. Electron. Eng., Central South Univ., Changsha, China, 2010.

[7] H. H. Hu, "A primary study of sound attenuation in suspended seawater," M.S. thesis, Institute of information science and engineering, Ocean University of China, Qingdao, China, 2007.

[8] S. D. Richards, "The effect of temperature, pressure, and salinity on sound attenuation in turbid seawater," The Journal of the Acoustical Society of America, vol. 103, no. 1, pp. 205-11, 1998.

[9] R. J. Urick, "The absorption of sound in suspensions of irregular particles," J. of the Acous. Soc. of America, vol. 20, p. 283, 1948.

[10] H. T. Wen et al., "Additional acoustic attenuation of coastal turbid water - Measurements compared with predictions using particle sizing distributions," Chinese J. of Acoustics, vol. 35, pp. 45-52, 2010.

[11] Q. Li, Digital Sonar Design in Underwater Acoustics, Springer, 2012.

[12] Y. Q. Xu, "The influence on sonar performance by suspended particles in shallow sea alongshore," M.S. thesis, Institute of information Science and Engineering, Ocean University of China, 2008.

[13] M. A. Ainslie, Principles of Sonar Performance Modeling, Springer, vol. 130, no. 6, pp. 41-71, 2010.

[14] B. W. Luo et al., "Development of the test-bed of pendulum single-beam ultrasound for detecting underwater micro-terrain," Research and Exploration in Laboratory, vol. 10, pp. 19-22, 2009.

[15] Z. H. Zhang et al., "Cobalt crust breaking and stripping simulation experimental device," Journal of Central South University: Science and Technology, vol. 42, p. 272, 2011.

[16] F. Y. Zhang et al., Classification and Nomenclature of Deep Sea Sediments, the Ocean Publishing Company, 2013.

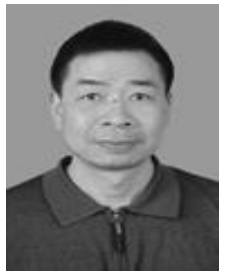

Haiming Zhao was born in Hunan. He received the B.S. degree in the Department of Mechanics from Central South University of Technology, Changsha, China, and the M.S. degree in the Department of Mechanics from Zhejiang University, Hangzhou, China, in 1988 and 1994, respectively.

$\mathrm{He}$ is currently an associate professor at the State Key Laboratory of High Performance Complex Manufacturing, Central South University, Changsha, China.

His research interest includes research on deep-sea exploration, and mechanical \& electrical integration.

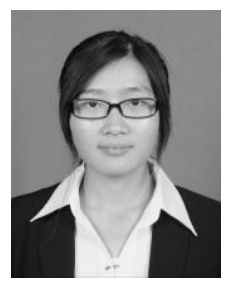

Yaqian Ji was born in Shandong. She received the B.S. degree in mechanical engineering from Shandong University of Science and Technology, Qingdao, China in 2013. She is currently working toward the M.S. degree in the Central South University.

Her research interests include underwater acoustic signal processing, analysis of underwater acoustic field, and active sonar system design.

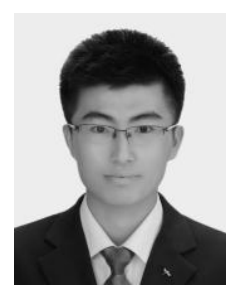

Qi Hao was born in Shandong. He received the B.S. degree in mechanical engineering from Central South University, Changsha, China in 2014. He is currently working toward the M.S. degree in the Central South University.

His research interests include underwater acoustic signal processing, circuit design of active sonar system, and acoustic techniques for cobalt-rich crust classification. 